\title{
Evaluación de características morfológicas e inmunofenotipo de células madre mesenquimales en cultivo obtenidas a partir de sangre de cordón umbilical y médula ósea.
}

\author{
Diana Páez Guerrero', Jenny Arévalo Romero', \\ Viviana Marcela Rodríguez Pardo'.
}

\begin{abstract}
'Laboratorio de Hematología. Grupo de investigación Inmunobiología y Biología Celular. Departamento de Microbiología. Facultad de Ciencias. Pontificia Universidad Javeriana.
\end{abstract}

Correspondencia: vivianar@javeriana.edu.co, vivianarodrigu@gmail.com

Recibido: 15-08-07 Aceptado: 30-11-07

\section{Resumen}

La sangre del cordón umbilical y la médula ósea humana son una alternativa para el aislamiento y cultivo de células madre mesenquimales, útiles en terapias de regeneración tisular e inmunomodulación. El objetivo de este trabajo fue aislar y cultivar células madre mesenquimales a partir de la sangre del cordón umbilical y de la médula ósea. Se recolectaron muestras de sangre de cordón umbilical en el servicio de Gineco-Obstetricia del Hospital Occidente de Kennedy en Bogotá, Colombia. La recolección de médula ósea se realizó en los servicios de ortopedia y traumatología del hospital universitario San Ignacio de Bogotá, Colombia. Se evaluó la tasa de generación celular, características morfológicas por microscopia invertida y tinción de Wright, asi como el inmunofenotipo de las poblaciones celulares por citometría de flujo.

La eficiencia de aislamiento de las células madre mesenquimales a partir de sangre de cordón umbilical fue del $30 \%$ con una tasa de generación entre 20 y 50 minutos. A partir de médula ósea el aislamiento fue del $100 \%$, con un tiempo de generación entre 16 y 39 minutos. Se observaron diferencias morfológicas por tinción de Wright y la presencia de progenitores hematopoyéticos durante el cultivo primario (3.54\% de CD34+/CD45+), que disminuían cuando se realizaba el primer pase del cultivo $(0.19 \%$ de CD34+/CD45+). El aislamiento de células madre mesenquimales es más eficiente a partir de medula ósea. Se observan diferencias morfológicas por microscopia invertida y tinción de Wright entre células aisladas de sangre de cordón umbilical y médula ósea. El antígeno CD105 constituye un marcador importante en el establecimiento del perfil inmunofenotípico de células madre mesenquimales.

Palabras clave: células madre, células mesenquimales, citometría de flujo, cordón umbilical, médula ósea.

\footnotetext{
Abstract

Bone marrow and umbilical cord blood are sources of mesenchymal stem cells. They are important for tissue regeneration and immunomodulation. The object of this work was to isolate and culture mesenchymal stem cells from bone marrow and umbilical cord blood cells. Bone marrow samples were obtained from patients at the
} 
Orthopedic Service of the San Ignacio Hospital and cord blood samples were obtained from women with normal pregnancy at the Gineco-Obstetrics Service of the Occidente de Kennedy Hospital in Bogotá, Colombia. We determined cellular rate generation, morphologic characteristics and antigens expression for cytometry flow.

Efficiency isolation was $30 \%$ for mesenchymal stem cells from umbilical cord blood and $100 \%$ for bone marrow, with cellular rate generation between 20 and 50 minutes and 16 and 39 minutes respectively. Morphologic differences were determined with microscopy and Wright coloration. During primary culture, $3.54 \%$ of CD34+/CD45+ was observed, but after 10 days, they were at $0.19 \%$ (CD34+/CD45+). Isolation of mesenchymal stem cells from bone marrow is efficient. There are differences between mesenchymal stem cells from umbilical cord blood and bone marrow. CD105 antigen is an important marker for mesenchymal cells lineage.

Keywords: bone marrow, flow cytometry, mesenchymal cells, stem cells, umbilical cord blood.

\section{Introducción}

Las propiedades biológicas de las células madre como autorenovación, plasticidad y regeneración tisular pueden ser utilizadas para su implementación en medicina regenerativa. En este grupo se destacan las células madre adultas, que pueden autorenovarse constantemente y dar origen a células especializadas para reparar eventualmente tejidos lesionados $(1,2)$. En la categoría de células madre adultas, se destacan las células madre hematopoyéticas, que han sido objeto de una extensa investigación ya que son responsables de la regeneración y mantenimiento de las células sanguíneas que se ubican en sangre periférica, médula ósea, hígado y timo (3) y las células madre mesenquimales, las cuales brindan el soporte necesario para regular la hematopoyesis a través de señales que inducen la diferenciación y proliferación de las células madre hematopoyéticas y su progenie por medio de interacciones directas célula a célula y la secreción de factores de crecimiento $(4,5)$.

Las células madre mesenquimales fueron inicialmente caracterizadas entre las décadas de los años 60's y 70's con los trabajos realizados por Friedenstein, quien las aisló de médula ósea y las describió como células adherentes de morfología fibroblastoide, capaces de diferenciarse hacia células de origen mesodérmico como osteocitos, condrocitos y adipocitos $(5,6)$. En el año 2006, la Sociedad Internacional de Terapia Celular ó ISCT (Internacional Society Cellular Therapy) propuso tres criterios para definir las células madre mesenquimales (CMM); primero, adherencia en cultivo; segundo, expresión de los antigenos CD73, CD90 y CD105 en ausencia de antigenos hematopoyéticos como CD34, CD45, marcadores de monocitos, macrófagos y linfocitos B; y tercero, capacidad de diferenciación in vitro en osteoblastos, adipocitos y condrocitos bajo condiciones estándar de cultivo $(7,8,9)$.

Adicional a lo propuesto por ISCT, también se debe tener en cuenta dos aspectos adicionales para clasificarlas como células madre; que las CMM realicen procesos de autorenovación, es decir, que durante la división celular solo una de las células hijas inicie programas de diferenciación celular, y además que sean capaces de desarrollar «plasticidad clonogénica»o diferenciación hacia tejidos de capas embrionarias diferentes a mesodermo como ectodermo y endodermo; de lo contrario seria necesario clasificarlas más como progenitores tempranos que como células madre $(2,10)$.

La médula ósea es la principal fuente de aislamiento de CMM, aunque se han aislado de tejido adiposo, páncreas, hígado, músculo esquelético, dermis, membrana sinovial, hueso trabecular (11-14), sangre de cordón umbilical (15), tejido pulmonar (16), pulpa dental y ligamento periodontal (17). No obstante, los tejidos más empleados son la medula ósea, la sangre de cordón umbilical y el tejido adiposo. En médula ósea el 0.003\% de las células mononucleares son CMM (5) y la literatura 
muestra un éxito de aislamiento del 100\% y formación de monocapa en cultivo entre 4 y 5 días $(13,14)$; sin embargo, se considera que las CMM obtenidas de esta fuente tienen una tasa de crecimiento que disminuye conforme se aíslan de donantes de edad avanzada, además solo se logra una capacidad de diferenciación osteogénica del $71.4 \%(11,13)$.

Contrario a la médula ósea, cuando se utiliza sangre de cordón umbilical para aislar y cultivar CMM, éstas células tienen una alta tasa de crecimiento y una capacidad de diferenciación osteogénica del 100\%, aunque su éxito de aislamiento está reportado solo entre $30 \%$ y $35 \%(11,13)$. En modelos experimentales se ha demostrado que las CMM son capaces de regenerar tejidos deteriorados o lesionados como hueso, cartílago, tejido hepático o miocárdico (18-20); y modular reacciones inmunes en colagenopatías, esclerosis múltiple y trasplantes de médula ósea (8).

Una de las principales aplicaciones clínicas de las CMM consiste en la reparación de hueso, demostrado in vivo en ratones y en caninos con defectos cráneofaciales y con defectos de huesos largos mediante la administración directa de CMM con matrices como hidroxiapatito/fosfato tricálcico (HA/TPC) $(21,22)$. Desde 1994 se han realizado protocolos estratégicos en ingeniería de tejidos para lograr diferenciar in situ de CMM en cartílago; estos procedimientos combinan éstas células con matrices biológicas activas y factores de crecimiento que inducen a la formación de condrocitos logrando importantes avances (18).

En la reparación de miocardio, se han postulado diferentes efectos de las CMM sobre el tejido cardiaco tales como la diferenciación local de ésta células en cardiomiocitos, liberación de factores solubles paracrinos que promuevan la proliferación de células residentes de tejido y/o la fusión de las CMM con células cardiacas. El modelo animal más usado para evaluar esta aplicación es el corazón porcino donde se ha observado una reducción importante del tamaño del tejido lesionado, neovascularización y reducción de los niveles de apoptosis
(23). Defectos congénitos en el músculo esquelético como distrofia muscular y otras miopatías pueden ser teóricamente restaurados con un transplante de CMM que mejoran la estructura y función del músculo. Las CMM obtenidas de la membrana sinovial han mostrado in vivo un potencial miogénico en el modelo de ratón mdx con distrofia muscular de Duchenne (24).

Además de las propiedades regenerativas de las CMM, también tienen la facultad de afectar el funcionamiento del sistema inmune. Estudios muestran que las CMM pueden inhibir la proliferación de linfocitos inducida por aloantígenos (25), mitógenos como fitohemaglutinina y concavalina A (26); así como la activación a través de anticuerpos anti CD3 y CD28 (27). Durante la maduración de células dendríticas, las CMM puede inhibir la expresión de moléculas involucradas en la presentación de antigenos como CD1a, CD40, CD80, CD86 y HLA-DR (28).

En Colombia los procedimientos relacionados con medicina regenerativa y el estudio de la biología de las células madre son insipientes y es necesario establecer sistemas de aislamiento y cultivo eficientes que permitan no solo la futura manipulación génica de estas células, sino establecer modelos para el estudio de los mecanismos que regulan su autorenovación y diferenciación, así como las diversas interacciones celulares que pueden ocurrir in vivo en los nichos donde residen éstas células. Por medio de este trabajo se estableció el aislamiento, cultivo, características morfológicas e inmunofenotipo de CMM de medula ósea y sangre de cordón umbilical, lo cual es un avance importante en la consolidación de ésta área de investigación en nuestro país y así permitir el uso de estas células con un mayor conocimiento de su biología.

\section{Materiales y métodos}

Las muestras de sangre de cordón umbilical (SCU) $(n=10)$ fueron recolectadas en sistema cerrado con anticoagulante CPDA (Baxter ${ }^{\circledR}$ ), a partir de mujeres entre 18 y 37 años de edad en estado de gravidez normal 
T abla 1.Características de recolección muestras sangre de cordón umbilical (SCU).

\begin{tabular}{cccc} 
Muestra & $\begin{array}{c}\text { Volumen } \\
\text { recolectado }\end{array}$ & $\begin{array}{c}\text { Tiempo de } \\
\text { procesamiento }\end{array}$ & $\begin{array}{c}\text { Semanas de } \\
\text { gestación }\end{array}$ \\
\hline SCU 001 & $80 \mathrm{~mL}$ & 14 horas & 42 semanas \\
\hline SCU 002 & $70 \mathrm{~mL}$ & 14 horas & 40 semanas \\
\hline SCU 003 & $80 \mathrm{~mL}$ & 13 horas & 38 semanas \\
\hline SCU 004 & $80 \mathrm{~mL}$ & 13 horas & 39 semanas \\
\hline SCU 005 & $100 \mathrm{~mL}$ & 12 horas & 40 semanas \\
\hline SCU 006 & $120 \mathrm{~mL}$ & 14 horas & 38 semanas \\
\hline SCU 007 & $100 \mathrm{~mL}$ & 13 horas & 40 semanas \\
\hline SCU 008 & $80 \mathrm{~mL}$ & 13 horas & 38 semanas \\
\hline SCU 009 & $80 \mathrm{~mL}$ & 12 horas & 36 semanas \\
\hline SCU 010 & $80 \mathrm{~mL}$ & 12 horas & 40 semanas \\
\hline
\end{tabular}

a término (38-40 semanas de gestación) que asistían al servicio de Gineco-Obstetricia del Hospital Occidente de Kennedy de Bogota, Colombia. Se recolectaron en total 10 muestras de SCU con un volumen promedio de $87 \mathrm{ml}$ y tiempo promedio de procesamiento de 13 horas después de su obtención, Tabla 1.

Para la recolección de médula ósea (MO) $(n=13)$, se contó con la colaboración de los servicios de ortopedia y traumatología del Hospital Universitario San Ignacio de Bogotá, Colombia, donde fueron tomadas las muestras a partir de pacientes sometidos a reemplazo total o parcial de cadera y/o procedimientos de osteosíntesis. Se obtuvieron 13 muestras de MO a partir de pacientes con edades comprendidas en 8 y 79 años y tiempo promedio de procesamiento de 6.6 horas después de su obtención, Tabla 2. La participación de los donantes en este estudio fue voluntaria con aceptación y firma del consentimiento para la donación de las muestras de SCU y MO. Las muestras obtenidas fueron procesadas y analizadas en el laboratorio de hematología de la Facultad de Ciencias de la Pontificia Universidad Javeriana, Bogotá, Colombia.

A partir de las muestras recolectadas se aislaron células mononucleares (gradiente de densidad con FicollHypaque $\left.{ }^{\circledR}\right)$ que luego eran cultivadas a $37^{\circ} \mathrm{C}$ y $5 \%$ de $\mathrm{CO}_{2}$ a una densidad de $1 \times 10^{6}$ células $/ \mathrm{cm}^{2}$ en medio de cultivo IMDM ${ }^{\circledR}$ (Medio Iscove modificado de Dulbecco) suplementado con $10 \%$ de suero fetal bovino, $1 \%$ de aminoácidos no esenciales, $1 \%$ piruvato de sodio, $0.5 \%$ de ciproxacilina y $0.1 \%$ de penicilina/estreptomicina. Después de 72 horas para MO y 6 días para SCU, las células no adherentes eran retiradas y una vez se observaba monocapa de células (confluencia mayor al $70 \%$ ), se procedía a realizar el desprendimiento de las 
T abla 2.Características de recolección muestras médula ósea (MO).

\begin{tabular}{|c|c|c|c|c|}
\hline Muestra & $\begin{array}{l}\text { Volumen } \\
\text { recolectado }\end{array}$ & $\begin{array}{l}\text { Edad } \\
\text { donante }\end{array}$ & $\begin{array}{l}\text { Procedimiento } \\
\text { quirúrgico }\end{array}$ & $\begin{array}{l}\text { Tiempo de } \\
\text { procesamiento }\end{array}$ \\
\hline MO 001 & $5 \mathrm{~mL}$ & 69 años & $\begin{array}{l}\text { Reemplazo de } \\
\text { cadera }\end{array}$ & 6 horas \\
\hline MO 002 & $61 \mathrm{~mL}$ & 59 años & $\begin{array}{l}\text { Reemplazo de } \\
\text { cadera }\end{array}$ & 7 horas \\
\hline MO 003 & $20 \mathrm{~mL}$ & 65 años & $\begin{array}{l}\text { Reemplazo de } \\
\text { cadera }\end{array}$ & 6 horas \\
\hline MO 004 & 21 & 23 años & $\begin{array}{l}\text { Osteosíntesis } \\
\text { fémur }\end{array}$ & 7 horas \\
\hline MO 005 & $5 \mathrm{~mL}$ & 79 años & $\begin{array}{l}\text { Reemplazo de } \\
\text { cadera }\end{array}$ & 9 horas \\
\hline MO 006 & $10 \mathrm{~mL}$ & 72 años & $\begin{array}{l}\text { Reemplazo de } \\
\text { cadera }\end{array}$ & 9 horas \\
\hline MO 007 & $20 \mathrm{~mL}$ & 8 años & $\begin{array}{l}\text { Osteosíntesis } \\
\text { fémur }\end{array}$ & 9 horas \\
\hline MO 008 & $20 \mathrm{~mL}$ & 12 años & $\begin{array}{l}\text { Osteosíntesis } \\
\text { fémur }\end{array}$ & 9 horas \\
\hline MO 009 & $20 \mathrm{~mL}$ & 15 años & $\begin{array}{l}\text { Osteosíntesis } \\
\text { fémur }\end{array}$ & 9 horas \\
\hline MO 010 & $27 \mathrm{~mL}$ & 74 años & $\begin{array}{l}\text { Reemplazo de } \\
\text { cadera }\end{array}$ & 7 horas \\
\hline MO 011 & $20 \mathrm{~mL}$ & 68 años & $\begin{array}{l}\text { Reemplazo de } \\
\text { cadera }\end{array}$ & 5 horas \\
\hline MO 012 & $20 \mathrm{~mL}$ & 9 años & $\begin{array}{l}\text { Osteosíntesis } \\
\text { fémur }\end{array}$ & 14 horas \\
\hline MO 013 & $72 \mathrm{~mL}$ & 42 años & $\begin{array}{l}\text { Reemplazo de } \\
\text { cadera }\end{array}$ & 6 horas \\
\hline
\end{tabular}

células adherentes con Tripsina $0.25 \%$ y EDTA $1 \mathrm{mM}$.

De las células desprendidas con una viabilidad celular superior al 95\%, se realizaba recuento en cámara de neubauer para calcular la tasa de generación celular(TGC), la evaluación morfológica con tinción de Wrigth en Cytospin (Shandon ${ }^{\circledR}$ ), inmunofenotipificación por citometría de flujo y finalmente un pase con 10.000 células $/ \mathrm{mL}$ para re-iniciar el cultivo. Para determinar el fenotipo de las células obtenidas, se siguió el criterio establecido la Sociedad Internacional de Terapia Celular ó ISCT (Internacional Society Cellular Therapy), evaluando la expresión de las proteínas CD90 y CD105 en ausencia de marcadores hematopoyeticos como CD34 y CD45 (fenotipo para CMM CD90+/CD105+/CD34-/CD45). Para ésto se utilizaron anticuerpos CD34FITC (clon BIRMA-K3 Dakocytomation ${ }^{\circledR}$ ), CD45PerCP (clon T29/33 Dakocytomation $\AA$ ), CD90PE (clon 5E10 Dakocytomation ${ }^{\circledR}$ ) y CD105APC (clon SN6 Ebioscience $囚$ ).

Como control fueron establecidos fibroblastos gingivales (CD90+/CD105+/CD34-/CD45-), células mononucleares de sangre periférica (CD90-/CD105+/ CD34-/CD45+) y células mononucleares de sangre de cordón umbilical (CD90 bajo/CD105-/CD34+/CD45+). 

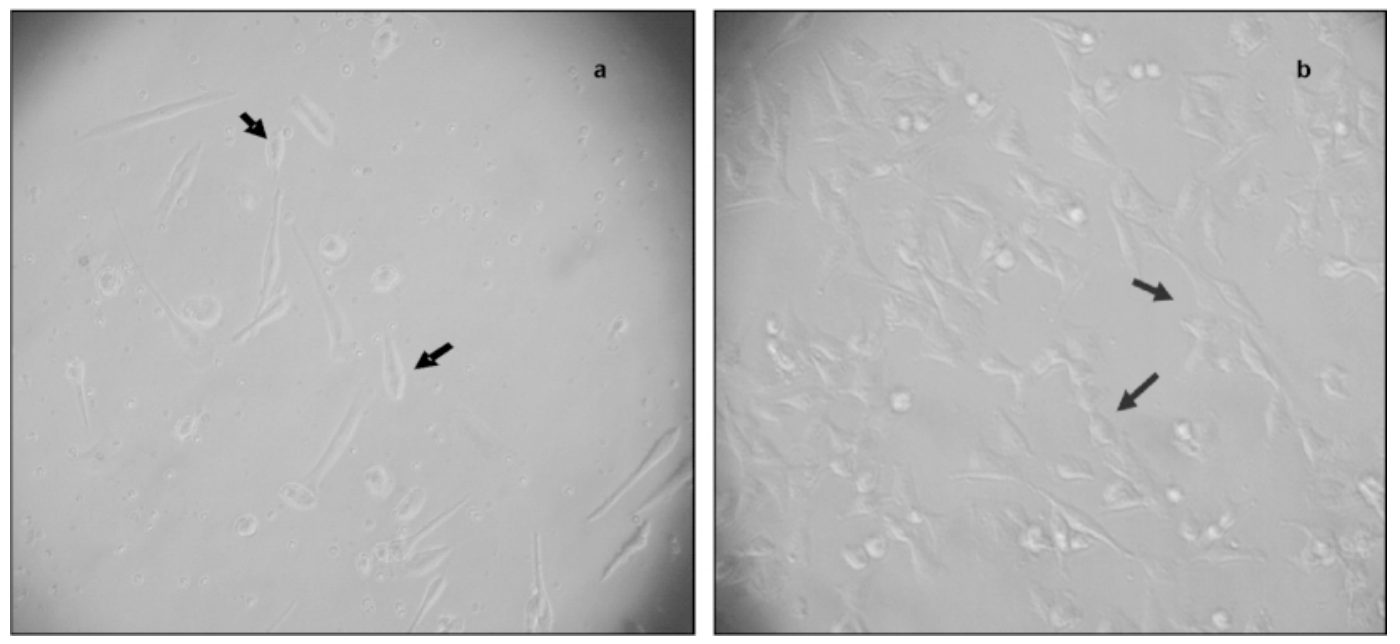

Figura 1. Células madre mesenquimales. Microscopia invertida 10x. a. Células obtenidas de sangre de cordón umbilical, nótese prolongaciones de tamaño medio. b. CMM aisladas de médula ósea con características fibroblastoides y prolongaciones prominentes.

Las muestras fueron adquiridas en el citómetro Facs Calibur $\mathrm{BD}{ }^{\circledR}$ y analizadas con el programa Cell Quest Pro ${ }^{\circledR}$ calculando el Indice Medio de Fluorescencia (IMF) para cada antigeno (29) y el porcentaje de células para el fenotipo establecido de CMM.

\section{Consideraciones éticas}

El estudio se realizó teniendo en cuenta la normatividad ética enunciada en la resolución 008430, capítulos IV y VI, expedida por el Ministerio de Salud en 1993, que regula «La investigación en mujeres en edad fértil, embarazadas, durante el trabajo de parto, puerperio, lactancia y recién nacidos; de la utilización de embriones, óbitos y fetos y de la fertilización artificial» y «De la investigación en órganos, tejidos y sus derivados, productos y cadáveres de seres humanos». La participación de los pacientes en este estudio fue voluntaria y sin ánimo de lucro. Los participantes recibían un consentimiento que explicaba de forma clara y precisa el objetivo de la toma de las muestras. Estos consentimientos informados fueron aprobados por el Comité de Investigación y Ética de la Facultad de Ciencias de la Pontificia Universidad Javeriana.

\section{Estadística}

Para el análisis de la expresión de los antígenos evaluados por citometría de flujo, se aplicó la prueba de Shapiro-Wilk para probar la normalidad de los datos (Índice Medio de Fluorescencia o IMF) mostrando una distribución no paramétrica $(\mathrm{CD} 34 \mathrm{p}=0.0164, \mathrm{CD} 45 \mathrm{p}=0.0022$, CD90 $\mathrm{p}=0.0957, \mathrm{CD} 105 \mathrm{p}=0.0025$ ), por lo cual se utilizó una prueba de Kruskal-Wallis que mostró una diferencia estadísticamente significativa del IMF durante los primeros días de cultivo $(\mathrm{p}=0.0040)$ y durante el primer pase de las células ( $\mathrm{p}=0.0001)$. El análisis se realizo en Statistix 7.0.

\section{Resultados}

Para el estudio se procesaron 10 muestras de SCU y 13 de MO, a partir de las cuales se obtuvo una eficiencia en la obtención de células con características fibroblastoides, relacionadas con CMM, del 30\% y $100 \%$ respectivamente. Se cumplieron los criterios de recolección de SCU según Bieback K y colaboradores (15) con respecto al tiempo de procesamiento de las muestras menor a 16 horas y al volumen de recolección mínimo de $30 \mathrm{~mL}$ como se muestra en la Tabla 1.

La tasa de generación celular se define como el tiempo (horas y/o minutos) necesario para que una población celular se duplique. Teniendo en cuenta esto, para las células aisladas de SCU la tasa de generación celular osciló entre 20 y 50 minutos, mientras que para las muestras de MO varió entre 16 y 39 minutos. En la Figura 1a se presenta el registro morfológico mediante microscopia invertida de células obtenidas de SCU, 

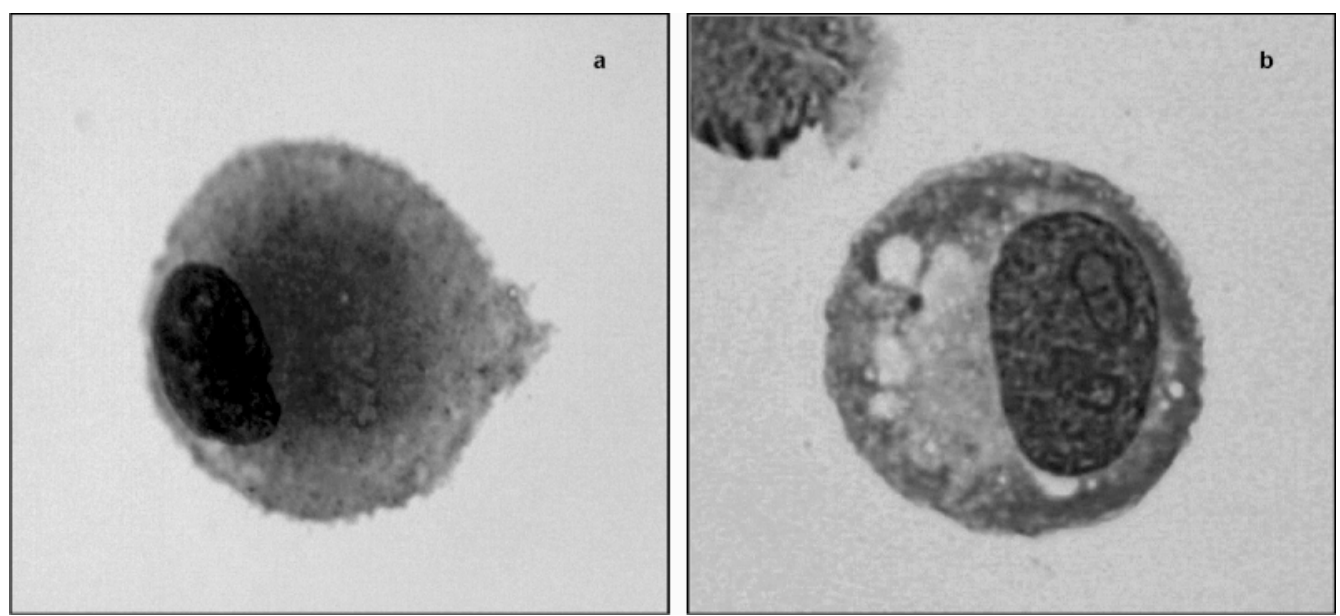

Figura 2. Células madre mesenquimales. Tinción de Wright. (a) CMM aisladas de sangre de cordón umbilical. (b) Células aisladas de MO. La diferencia más importante entre las dos poblaciones estudiadas esta dada por la presencia de nucleolos y vacuolas citoplasmáticas.
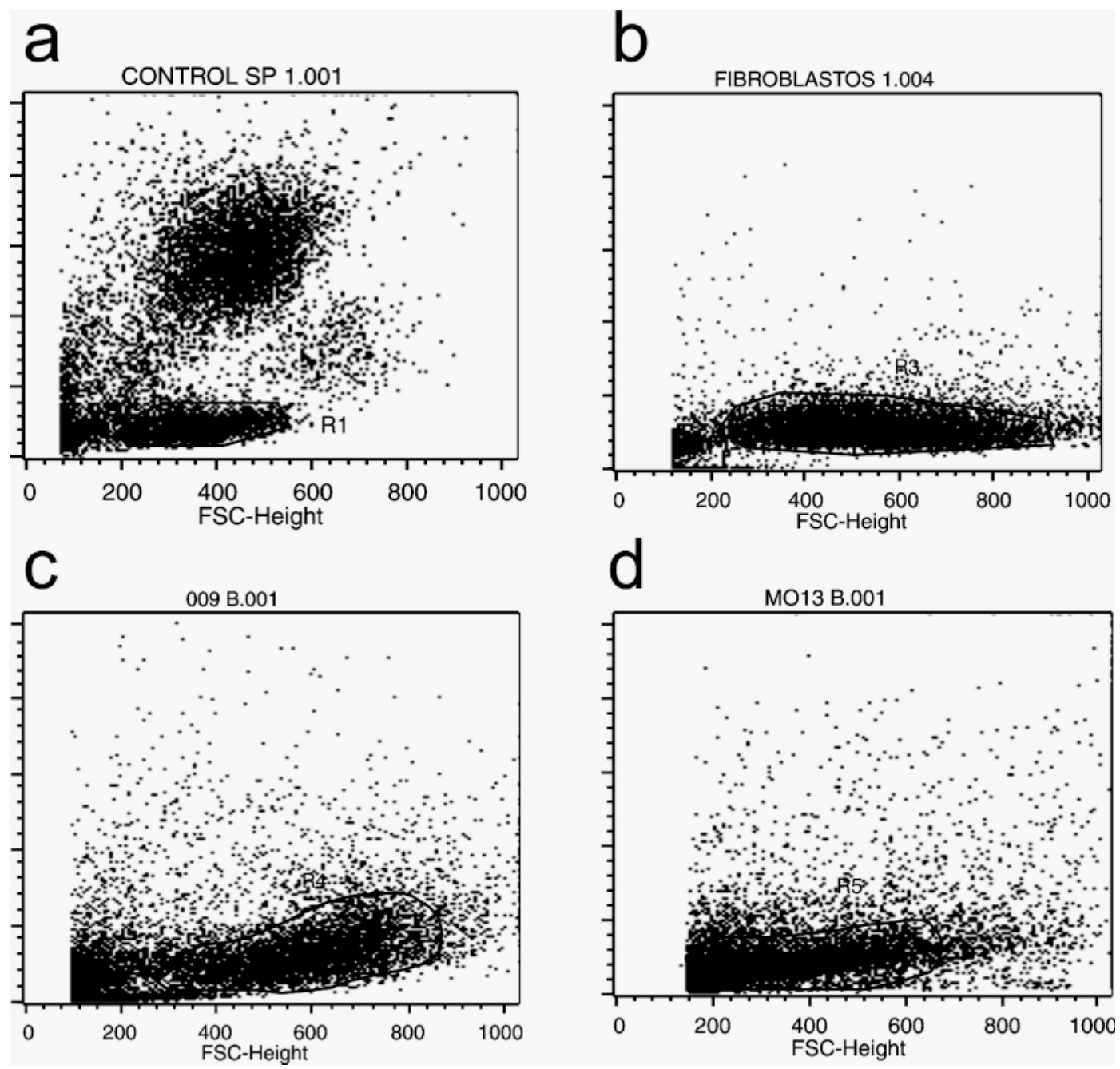

Figura 3. Gráfica de puntos (dot plots) poblaciones celulares seleccionadas. Se indica la región seleccionada para el análisis de cada una de las poblaciones control y experimentales. (a) control células mononucleares de sangre periférica (CD34-/CD45+/CD90-/CD105+). (b) control fibroblastos gingivales (CD34-/CD45-/CD90+/CD105+). (c) CMM cultivo primario (10 dias). (d) CMM cultivo 1er fase. 

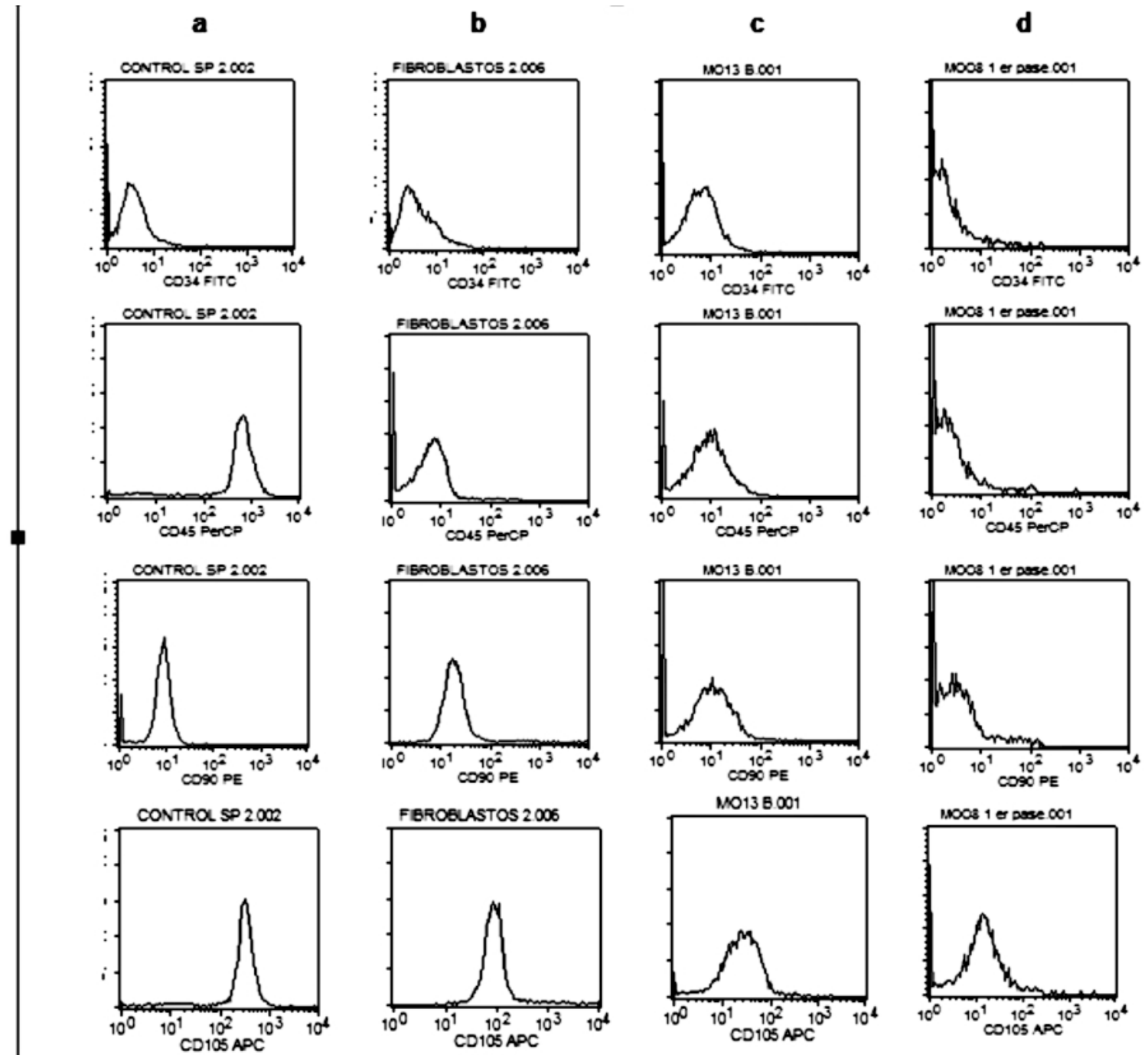

FBROELASTOS 2006
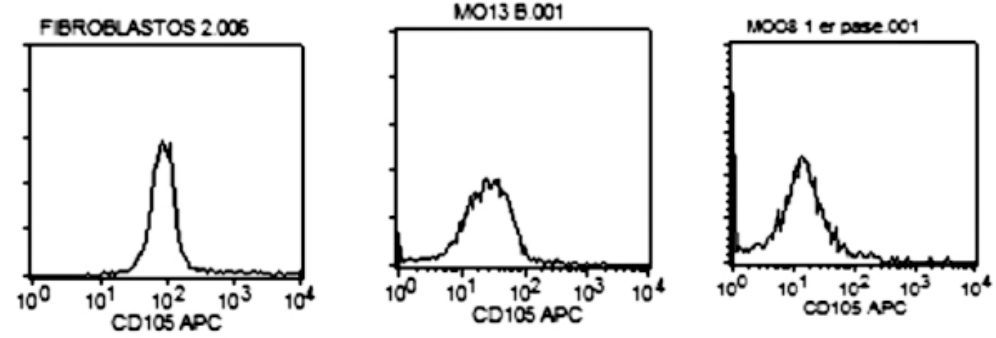

Figura 4. Análisis de la expresión de antígenos relacionados con células madre mesenquimales (CMM). Este análisis fue realizado a partir de cada una de las regiones respectivas presentadas en la figura 3. a. control células mononucleares de sangre periférica (CD34-/CD45+/ CD90-/CD105+). b. control fibroblastos gingivales (CD34-/CD45-/CD90+/CD105+). c. CMM cultivo primario (10 dias). d. CMM cultivo 1er pase.

donde se observan células con características fibroblastoides con prolongaciones de tamaño medio, mientras que para las derivadas de MO se observaron células con prolongaciones más extensas Figura $1 \mathrm{~b}$.

Respecto a la evaluación mediante tinción con Wright, tanto para las células derivadas de SCU Figura 2a como para las de MO Figura 2b, se observaron células de gran tamaño con un núcleo redondo excéntrico, un citoplasma basófilo y desprovisto de granulaciones o inclusiones; la diferencia radica en la presencia de nucleolos y algunas vacuolas en el citoplasma de las células derivadas de MO.
Durante la inmuno-fenotipificación por citometría de flujo se utilizaron como control células mononucleares de sangre periférica (CD34-/CD45+/CD90-/CD105+) y fibroblastos gingivales (CD34- / CD45- / CD90 low / CD105+), las Figuras 3a y 3 b muestra los diferentes dot plot seleccionados para el estudio de cada una de las poblaciones control, las cuales mostraron los fenotipos esperados Figura $4 \mathrm{a}$ y $4 \mathrm{~b}$.

En las figuras $3 \mathrm{c}$ y $3 \mathrm{~d}$ se observan los dot plot analizados de las poblaciones mesenquimales obtenidas cuyo fenotipo se presenta en las figura $4 \mathrm{c}$ y $4 \mathrm{~d}$, donde 


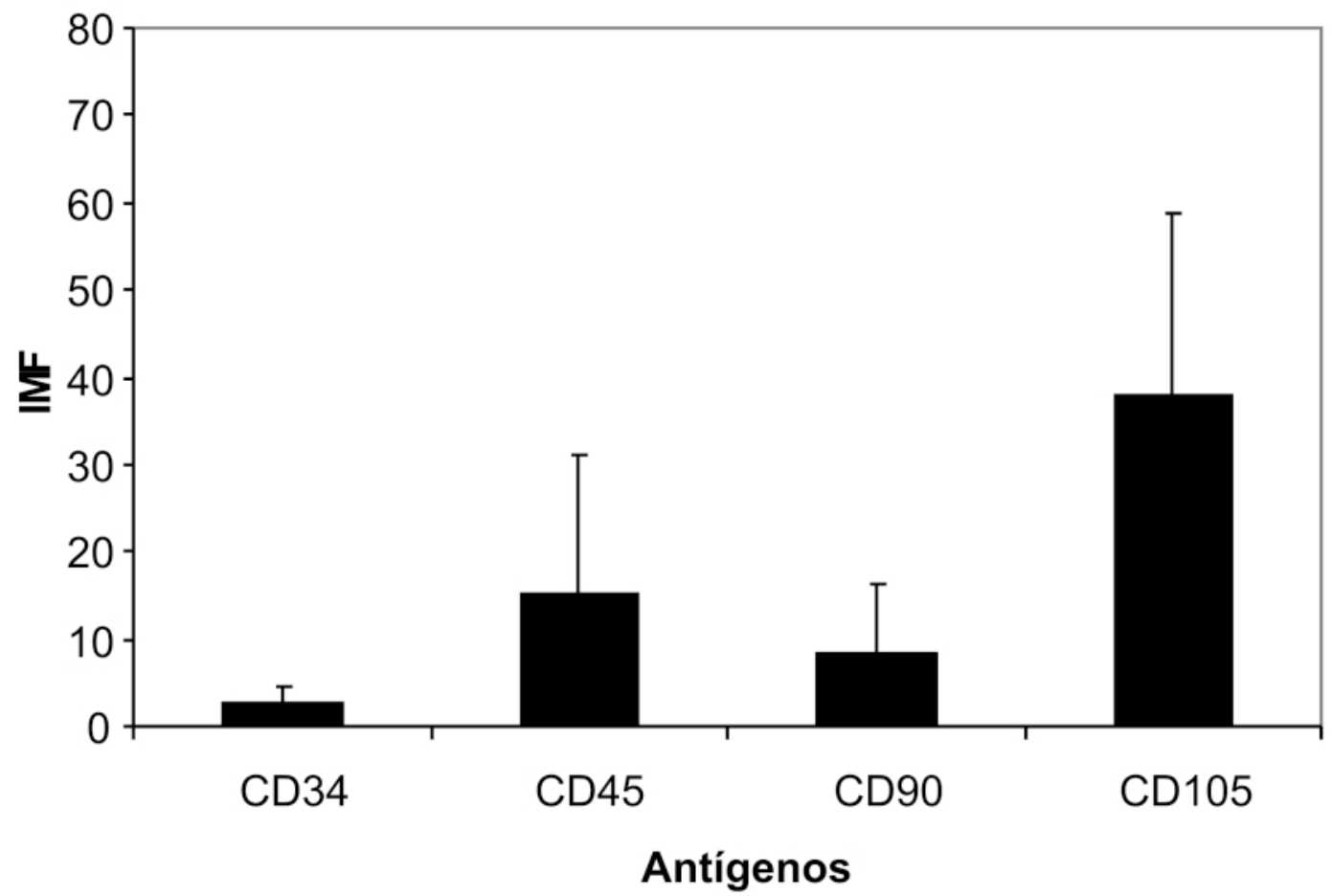

Figura 5. Indice medio de fluorescencia. Cultivo primario. Se observa la expresión de los antígenos CD34 y CD45 durante los primeros días de cultivo.

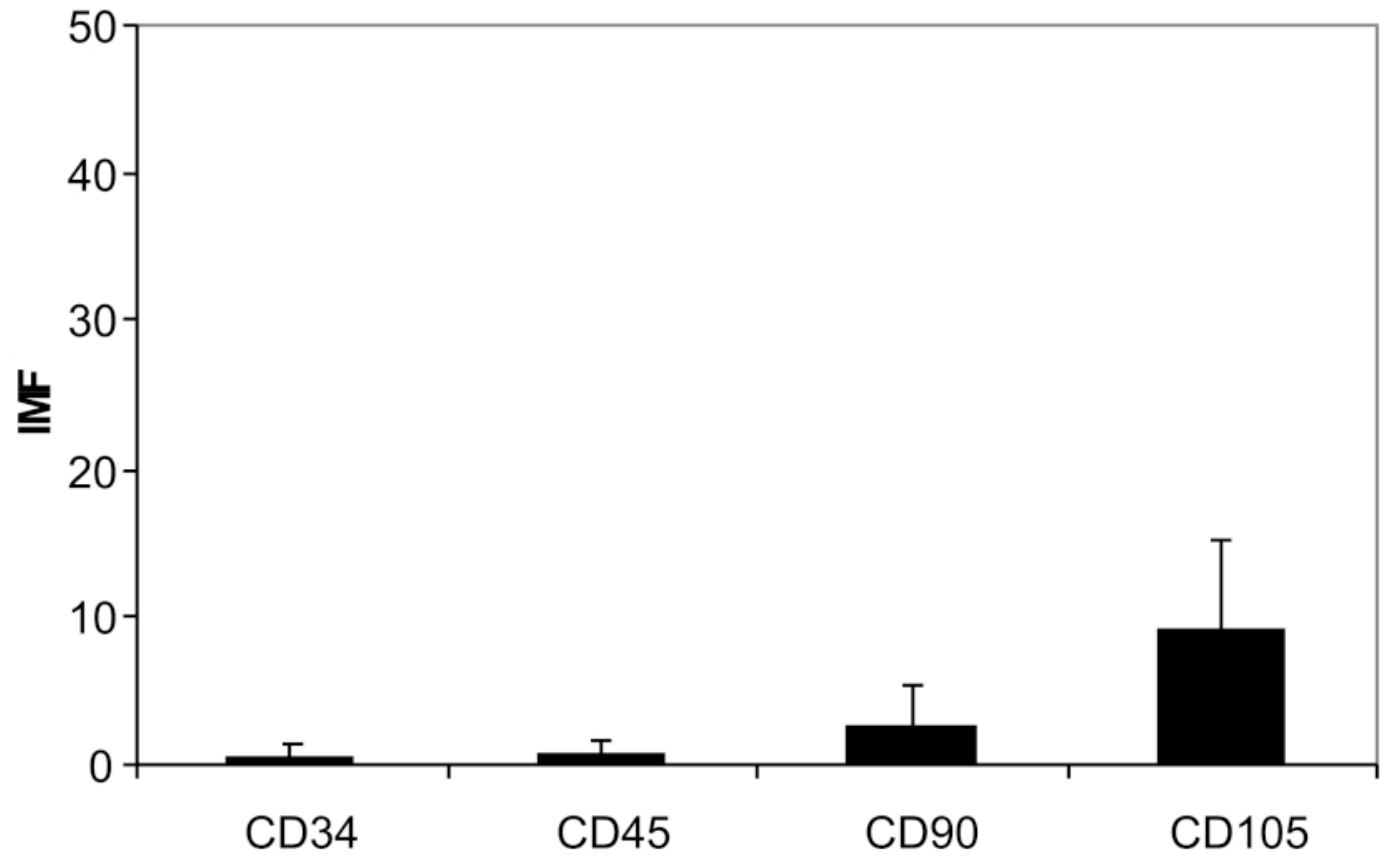

Antígenos

Figura 6. Índice medio de fluorescencia. Cultivo primer pase. La expresión de los antígenos hematopoyéticos CD34 y CD45 disminuye notablemente, mientras que el antígeno CD105 se mantiene. 


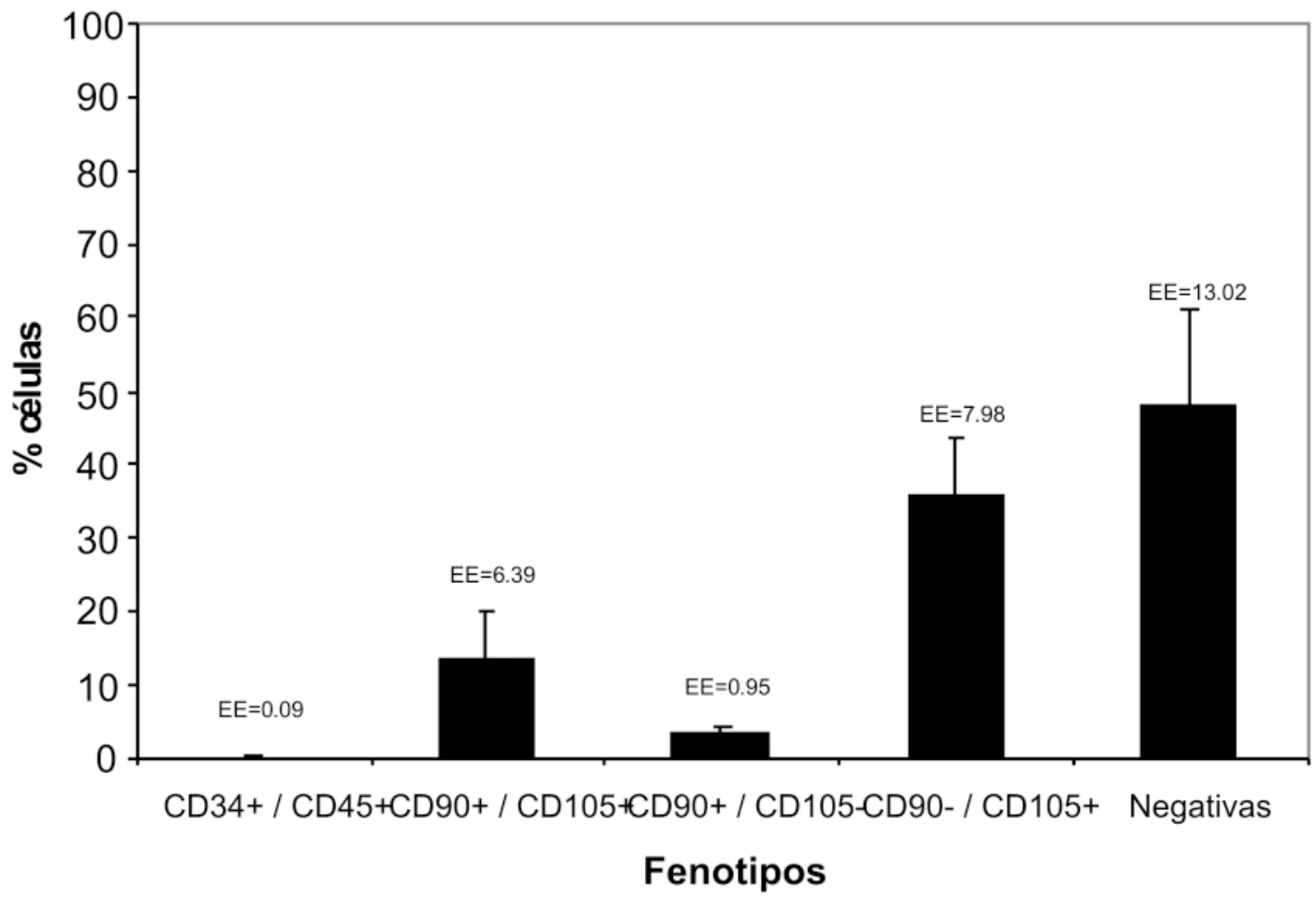

Figura 7. Porcentaje de células relacionado con fenotipo de células madre mesenquimales. Cultivo primario. Durante los primeros 10 días de cultivo se obtiene una población heterogénea, con presencia de progenitores hematopoyéticos CD34+/CD45+ y CD90+/CD105-, así como células negativas, que representan el $8.48 \%$ y $29.87 \%$ respectivamente de la población total.

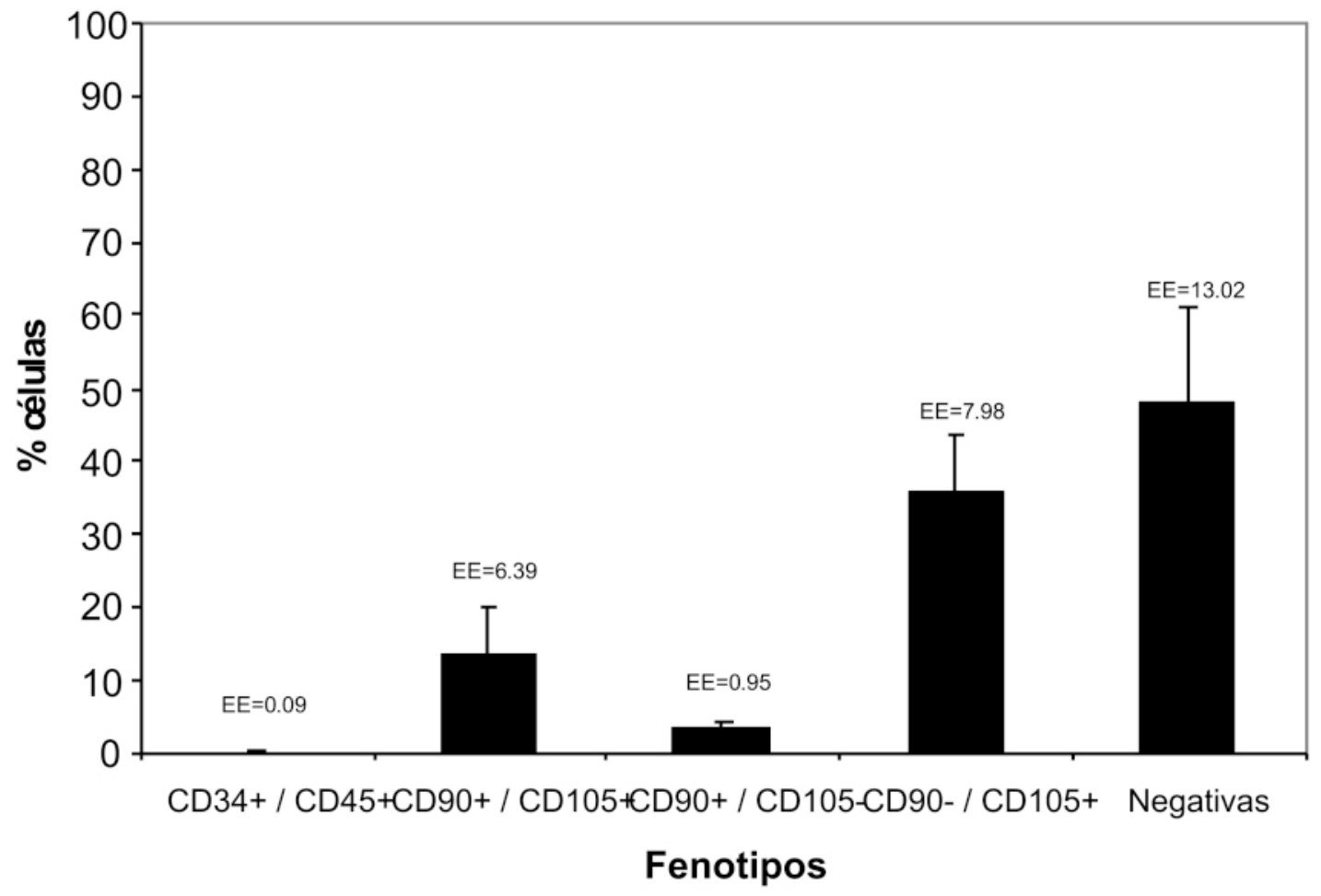

Figura 8. Porcentaje de células relacionado con el fenotipo de células madre mesenquimales. Cultivo primer pase. Después de realizar el primer pase, el porcentaje de células hematopoyéticas disminuye notablemente $(0.19 \%)$, con incremento de la población CD90-/CD105+ (35.42\%) en comparación al cultivo primario que presentaba $21.25 \%$ de la población total con este fenotipo. 
se observa la expresión de los antígenos evaluados a partir del cultivo primario y en células obtenidas después del primer pase de CMM aisladas de MO. No se logró realizar citometría de flujo para las CMM derivadas de sangre de cordón umbilical, debido a que al analizar las muestras en los parámetros SSC/FSC se observó una alta dispersión celular que no permitió establecer una población homogénea. Se calculó el Índice Medio de Fluorescencia (IMF) para cada antigeno (29) y el porcentaje de células para el fenotipo establecido de CMM. En la Figura 5 se presenta el IMF calculado para los antigenos CD34, CD45, CD90 y CD105 en las células obtenidas del cultivo primario; mostrando una diferencia estadísticamente significativa ( $\mathrm{p}=0.0040)$ en la expresión de estos antigenos; de forma similar, también se observaron diferencias significativas en el IMF de las células obtenidas en el primer pase $(\mathrm{p}=0.0001)$ Figura 6 .

Durante el cultivo primario la distribución del porcentaje de células fue de 3.54\% CD34+/CD45+, 40.39\% CD90+/ CD105+, 4.95\% CD90+/CD105-, 21.25\% CD90-/ CD105+, negativas $29.87 \%$ de la población total, Figura 7. Luego de realizarse el primer pase de las CMM aisladas, se obtuvo $0.19 \%$ CD34+/CD45+, 13.34\% CD90+/ CD105+, 3.20\% CD90+/CD105-, 35.42\% CD90-/ CD105+, negativas $47.85 \%$, Figura 8.

\section{Discusión}

El estudio de las células madre mesenquimales inició a mediados de los años 60's y se expandió durante la década de los 70's, con los trabajos realizados por Friedstein (5), quien describió por primera vez una población de células adherentes de medula ósea que formaban parte del estroma medular, con características fibroblastoides denominadas unidades formadoras de colonias de fibroblastos (UFC-F) (6). En la última década varios estudios caracterizaron este grupo de células, mostrando que MO, SCU y tejido adiposo constituyen fuentes importantes de obtención, lo que permitió el estudio comparativo de estos tejidos $(13,14)$.

En nuestro trabajo encontramos que a partir de MO la eficiencia de aislamiento de CMM corresponde al
$100 \%$, en contraste con un $30 \%$ en SCU, lo que coincide con la literatura. De manera similar, el establecimiento de la TGC para las dos poblaciones (SCU y MO) mostró que las células de MO tardan menos tiempo en proliferar, reafirmando que éstas son una fuente de obtención significativa; aunque es importante considerar que los datos obtenidos para el análisis de tasa de generación celular son relativos, ya que se estimó el recuento inicial de CMM según lo reportado en la literatura, es decir, $0.003 \%$ de CMM en MO (5).

Los hallazgos morfológicos que presentamos por microscopia invertida, coinciden con lo reportado por Wagner y colaboradores sobre las diferencias morfológicas de CMM según la fuente de obtención; ya que a partir de SCU las células toman una configuración de fibroblastos cortos contrario a lo observado en las células aisladas de MO. Este aspecto morfológico es de gran importancia ya que podría tener relación con el inmunofenotipo de estas células, Chang y colaboradores muestran que si la población mesenquimal es obtenida de sangre de cordón umbilical la gran mayoría no expresan el antigeno CD90 mientras que si la población es de origen medular este marcador es determinante en su identificación, lo que podría explicar en parte los contradictorios resultados que se encuentran publicados con respecto a la expresión de ésta y otras proteínas en células madre mesenquimales (30).

Aunque por microscopia invertida existen antecedentes en la literatura sobre la morfología de las CMM, es la primera vez que se presenta su conformación con tinción de Wrigth, mostrando que en suspensión las CMM son de un tamaño superior a los fibroblastos con los que usualmente se comparan. En el análisis morfológico de las CMM con tinción con Wright se presentan muy pocas diferencias entre las derivadas de SCU y MO. El citoplasma se observa basófilo y desprovisto de granulaciones o inclusiones, sin embargo, en algunas fotografías las células de médula ósea presentan vacuolas lo que podría indicar algún tipo de stress celular que posiblemente podría ser modificado 
con el uso de factores de crecimiento como el Factor de Crecimiento de Fibroblastos-â (FGF-â).

Durante la inmunofenotipificacion de las células obtenidas, se detectó la expresión de antigenos relacionados con progenitores hematopoyeticos en el cultivo primario; sin embargo, en la determinación realizada a partir del primer pase, tanto la expresión (IMF) como el porcentaje de células hematopoyéticas disminuyeron notablemente lo que podría mostrar que los diferentes pases del cultivo podrían tener un efecto sobre su pureza. No obstante, aunque CD90 es considerado un marcador de linaje para CMM, su expresión es detectable en células hematopoyéticas por lo que no constituye un marcador especifico, contrario a lo que observamos con respecto a la proteína CD105, cuya expresión se mantiene en las células adherentes obtenidas en el primer pase del cultivo. En substitución de la proteína CD90 para fenotipificar CMM, es posible considera la detección de STRO-1, que es altamente expresado en CMM de estroma medular; aunque es de considerar que su expresión se limita a poblaciones de primitivas o no diferenciadas $(31,32)$.

Con la finalidad de optimizar la tasa de generación celular y la duración de las células in vitro, es importante considerar en cultivo la implementación factores de crecimiento como factor de crecimiento derivado de plaquetas (PDGF), factor de crecimiento epidermal (EGF), factor de crecimiento de fibroblastos, factor de crecimiento transformante beta (TGF- â) y factor de crecimiento similar a la insulina-1; además, es importante estudiar las CMM en el contexto de nicho particulares y no generalizar su uso terapéutico sin considerar las variaciones observadas según de la fuente de obtención, número de células utilizadas y microambiente donde se desean utilizar, ya que es demostrado que aunque las CMM es considerada una población particular, sus características biológicas y funcionales varían notablemente de acuerdo a su lugar de origen.

\section{Agradecimientos}

Agradecemos a los pacientes, al equipo médico y de enfermería del Hospital Universitario San Ignacio, especialmente al departamento de Ortopedia; así como al Hospital Occidente de Kennedy por su cooperación con este proyecto. Al grupo de Inmunobiología y Biología Celular por el apoyo brindado a la Línea de Investigación «Biología de las Células Madre» de la Facultad de Ciencias de la Pontificia Universidad Javeriana.

\section{Conflicto de intereses}

Esta investigación es de carácter exclusivamente académico, por lo tanto, no presenta conflicto de intereses con la empresa pública o con la empresa privada.

\section{Referencias}

1. Körbling M, Estrov Z. Adult stem cells for tissue repair - a new therapeutic concept?. N Engl J Med. 2003;349:570-582.

2. Rodríguez V. Células Madre:Conceptos Generales y Perspectivas de Investigación. Universitas Scientiarum. 2005; 10:5-14.

3. Szilvassy S. The biology of hematopoietic stem cells. Arch Med Res. 2003; 34: 446-60.

4. Kang X, Zang W, Bao L, Li D, Xu X, Yu X. Differentiating characterization of human umbilical cord blood derived mesenchymal stem cells in vitro. Cell Biol Int. 2006;30:569-575.

5. Beyer N, Da Silva L. Mesenchymal Stem Cells: Isolation in vitro expansion and characterization. Handb Exp Pharmacol. 2006; 174:249-282.

6. Gregory C, Prockop D, Spees J. Non-hematopoietic bone marrow stem cells: Molecular control of expansion and differentiation. Exp Cell Res. 2005; 306:330-335

7. Bianco P, Riminucci M, Gronthos S, Robey P. Bone Marrow Stromal Cells: Nature, biology, and potencial applications. Stem Cells. 2001; 19: 180-92.

8. Rasmusson I. Immune modulation by mesenchymal stem cells. Exp Cell Res. 2006;312:2169-2179.

9. Deans RJ, Moseley AB. Mesenchymal Stem Cells: Biology and potential clinical uses. Exp Hematol. 2000;28:875-884.

10. Lakshmipathy U, Verfaille C. Stem Cell Plasticity. Blood Rev. 2005; 19:29-38

11. Wexler S, Donaldson C, Denning P, Rice C, Bradley B, Hows J. Adult bone marrow is a rich source of human mesenchymal «stem» cells but umbilical cord and mobilized adult blood are not. Br J Haematol. 2003;121:368-374. 
12. Baksh D, Song L, Tuan RS. Adult mesenchymal stem cells: characterization, differentiation, and application in cell and gene therapy. J Cell Mol Med. 2004;8:301-316.

13. Wagner W, Wein F, Seckinger A, Frankhauser M, Wirkner U et al. Comparative characteristics of mesenchymal stem cells from human bone marrow, adipose tissue, and umbilical cord blood. Exp Hematol. 2005; 33:1402-1416.

14. Kern S, Eichler H, Stoeve J, Klüter H, Bieback K. Comparative analysis of mesenchymal stem cells from bone marrow, umbilical cord blood, or adipose tissue. Stem Cells. 2006;24:1294-1301.

15. Bieback K, Kern S, Klüter H, Eichler H. Critical parameters for the isolation of mesenchymal stem cells from umbilical cord blood. Stem Cells. 2004; 22:625-634.

16. Sabatini F, Petecchia I, Tavian M, Jodon V, Rossi G, BroutyBoye D. Human bronchial fibroblast exhibit a mesenchymal stem cell phenotype and multilineage differentiating potentialities. Lab Invest. 2005;85:962-971.

17. Shi S, Bartold P, Miura M, Seo B, Robey P, Gronthos S. The efficacy of mesenchymal stem cells to regenerate and repair dental structures. Orthod Craniofac Res. 2005;8:191-199.

18. Krampera $\mathrm{M}^{\mathrm{a}}$, Pizzolo G, Aprili G, Franchini M. Mesenchymal stem cells for bone, cartilage, tendon and skeletal repair. Bone. 2006;39:678-683.

19. Krampera $\mathrm{M}^{\mathrm{b}}$, Pasini A, Pizzolo G, Cosmi L, Romagni S, Annunziato. Regenerative and immunomodulatory potential of mesenchymal stem cells. Curr Opin Pharmacol. 2006;6:435-441.

20. Kassem M, Kristiansen M, Abdallah B. Mesenchymal Stem Cells:Cell biology and potential use in therapy. Basic Clin Pharmacol Toxicol. 2004; 95:209-214.

21. Mankani MH, Kuznetsov SA, Fowler B, Kingman A, Robey PG. In vivo bone formation by human bone marrow stromal cells: effect of carrier particle size and shape. Biotechnol Bioeng. 2001;72:96-107.

22. Tsuchida H, Hashimoto J, Crawford E, Manske P, Lou J. Engineered allogeneic mesenchymal stem cells repair femoral segmental defect in rats. J Orthop Res. 2003;21:44-53.
23. Mazhari R, Hare JM. Mechanisms of action of mesenchymal stem cells in cardiac repair: potential influences on the cardiac stem cell niche. Nat Clin Pract Cardiovasc Med. 2007;4:S21-S26.

24. De Bari C, Dell' accio F, Vandenabeele F, Vermeesch IR, Raymackers JM, Luyten FP. Skeletal muscle repair by adult human mesenchymal stem cells from synovial membrane. Blood Rev. 2006;200:161-171.

25. Tse WT, Pendleton JD, Beyer WM, Egalka MC, Guinan EC. Suppresion of allogenic T-cell proliferation by human marrow stromal cells: implications in transplantation. Transplantation. 2003;75:389-397.

26. Le Blanc K, Tammik I, Sundberg B, Haynesworth SE, Ringden O. Mesenchymal stem cells inhibit and stimulate mixed lymphocyte cultures and mitogenic responses independently of the major histocompatibility complex. Scand J Immunol. 2003;57:11-20.

27. Aggarwal S, Pittenger MF. Human mesenchymal stem cells modulate allogenic immune cell responses. Blood. 2005; $105: 1815-1822$

28. Zhang W, Ge W, Li C, You S, Liao I, Han Q et al. Effects of mesenchymal stem cells on differentiation, maduration, and function of human monocyte-derived dendritic cells. Stem Cells Dev. 2004;13:263-271.

29. Maurillo L, Del Poeta G, Venditti A, Bucciana F, Battaglia A, Santinelli S et al. Quantitative analisis of Fas and Bcl-2 expression in haematopoietic precursors. Haematologica. 2001;86:237-243.

30. Chang Y, Tseng C, Hsu I, Hsieh T, Hwang S. Characterization of two populations of mesenchymal progenitor cells in umbilical cord blood. Cell Biol Int. 2006;30:495-499.

31. Kortesidis A, Zannettino A, Isenmann S, Shi S, Lapidot T, Gronthos S. Stromal-derived factor-1 promotes the growth, survival, and development of human bone marrow stromal cells. Blood. 2005;105:3793-3801

32. Gonçalves R, Da Silva C, Cabra J, Zanjani E, Almeida-Porada G. A Stro-1+ human universal stromal feeder layer to expand/maintain human bone marrow hematopoietic stem/progenitor cells in a serum-free culture system. Exp Hematol. 2006;34:1353-1359.
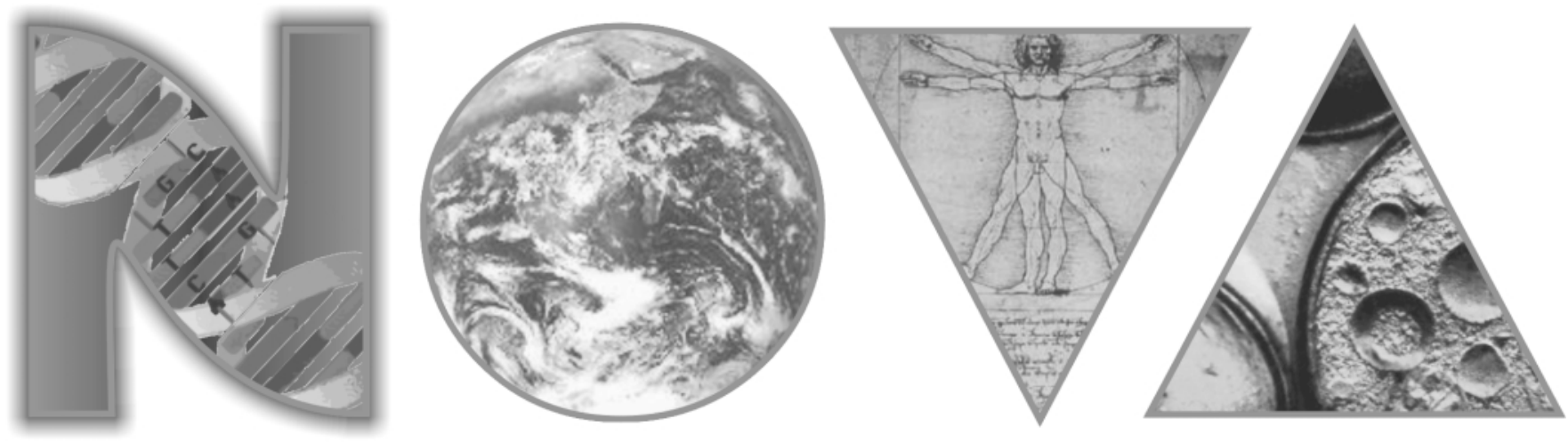